\title{
Gênero e representação política: recrutamento para "pos- tos críticos" em oito países latino-americanos
}

\author{
Allysson Eduardo Botelho Oliveira ${ }^{1}$
}

\begin{abstract}
Resumo: 0 artigo tem como objetivo desenvolver análise exploratória para identificar os critérios de recrutamento "postos críticos", cargos políticos capazes de influenciar o processo de tomada de decisão no Legislativo (Câmaras Baixas), em oito países latino-americanos: Argentina, Brasil, Bolívia, Costa Rica, Equador, México, Paraguai e Uruguai. A análise está organizada da seguinte forma: na primeira seção há a caracterização dos postos críticos, bem como a identificação das peculiaridades que tais postos podem assumir nos diversos legislativos analisados. Em seguida explicitamos as fontes e os métodos utilizados na pesquisa e, na última seção são apresentados e discutidos os resultados da pesquisa, que indicam que o percentual de mulheres na legislatura é uma variável relevante para se avaliar o recrutamento de mulheres para os postos críticos.
\end{abstract}

Palavras-chave: Poder Legislativo; gênero; América Latina.

\section{Introdução}

0 presente artigo está vinculado à pesquisa "Representação política das mulheres na América Latina", cujo objetivo geral é identificar quais variáveis relacionadas à organização do processo decisório (aspectos procedimentais) explicam o acesso a postos críticos. Esses podem ser definidos como:

\begin{abstract}
“(...) cargos dotados de recursos e prerrogativas especiais, como posição de first mover, capacidade de definir quando a decisão deverá ser tomada, por que atores, através de quais mecanismos, além da própria sequência do processo decisório, dimensões associadas à agenda setting. Tais recursos e prerrogativas ampliam a capacidade dos ocupantes de tais cargos influenciarem o processo decisório, estabelecendo uma hierarquia ou desigualdade com relação a membros ordinários (não ocupantes de tais cargos). (...)" (Rezende, 2013, pg.30).
\end{abstract}

A noção de postos críticos se diferencia do conceito de atores com poder de veto (TSEBELIS, 2002) porque não considera as preferências dos atores, elemento central nesse último. Ademais, a ideia de postos críticos remete ao debate sobre "massa crítica" e "atos críticos", relacionando à representação política de mulheres, em sua dimensão descritiva e substantiva, respectivamente.

A primeira espécie de representação pode ser compreendida como a corres-

10 presente trabalho recebeu menção honrosa no Simpósio de Integração Acadêmica de 2013. Versão preliminar foi apresentada como relatório final do Programa Jovens Talentos para Ciência/CAPES, responsável pelo financiamento dessa etapa da pesquisa 
pondência entre representantes e representados, estando relacionada ao percentual de mulheres na legislatura. Por sua vez, a dimensão substantiva pode ser entendida como a realização, pelo representante, das preferências e interesses do representado (PITKIN, 1967). A representação descritiva, contudo, não necessariamente implica em representação substantiva.

Para que esta se torne efetiva, faz-se necessário, além do aspecto meramente quantitativo, a presença de características institucionais favoráveis à atuação das parlamentares (REZENDE, 2015). Desse modo, a própria estruturação do processo decisório no interior dos legislativos pode influenciar o acesso aos postos críticos, cargos que, haja vista suas prerrogativas, viabilizariam o exercício da representação substantiva.

Nesse diapasão, o principal objetivo do artigo é perquirir acerca da influência de tais características institucionais no acesso aos postos críticos por parlamentares do sexo feminino, melhor dizendo, buscar-se-á responder à seguinte indagação: o grau de centralização do processo de tomada de decisão nas câmaras baixas de oito legislativos latino-americanos - Argentina, Brasil, México, Costa Rica, Paraguai, Uruguai, Bolívia e Equador - influencia no acesso aos postos críticos por parlamentares do sexo feminino?

Quatro serão as variáveis utilizadas para aferir o nível de centralização, quais sejam: (i) quem estabelece a ordem do dia? (ii) qual é a maioria necessária para alteração da ordem do dia? (iii) há a possibilidade de votação de projetos sem discussão prévia nas comissões? (iv) qual é o quórum necessário para a restrição do debate antes da votação final de um projeto de lei no plenário?

Quanto maior o número de parlamentares necessário para a tomada de quaisquer das decisões supracitadas, mais descentralizado será o processo legislativo, uma vez que o poder decisório caberá a um número maior de atores políticos. Cumpre esclarecer que, para efeitos de análise estatística, os postos críticos serão restringidos às presidências das comissões permanentes.

\section{Revisão da Literatura}

Para tratar da organização do processo decisório no Legislativo, recorremos ao trabalho de Cox (2005) que afirma a necessidade de se inserir uma hierarquia no Parlamento, a partir da criação de cargos políticos especiais para que se possa superar o "estado de natureza legislativo", situação em que a total igualdade dos parlamentares impossibilitaria a existência de ordem e, consequentemente, a efetividade do processo de tomada de decisão.

Assim, os parlamentares devem ser iguais em relação ao poder de voto (cada 
parlamentar simboliza um voto), mas desiguais no que diz respeito aos poderes de agenda, que são as prerrogativas necessárias para a organização do processo de tomada de decisão.

Destacaremos aqui a contribuição de três perspectivas - distributivista, informacional e partidária - que buscam explicar a distribuição de postos críticos. Em seu conjunto, essas correntes compõem o que se convencionou chamar novo institucionalismo, perspectiva analítica bastante difundida na Ciência Política, que apresenta as seguintes características: "as instituições que organizam o processo decisório são (a) elas mesmas responsáveis pela estabilidade dos resultados obtidos e (b) influenciam os resultados políticos substantivos." (LIMONGI, 1994). Isso significa que "as instituições importam" porque garantem a estabilidade das decisões políticas, na medida em que limitam estratégias de ação e resultados possíveis, atuando como quadro de referência para os atores políticos.

Esse trabalho se concentra no estudo do processo decisório a partir da ênfase em postos críticos, os critérios de seleção para os mesmos e suas prerrogativas. Considera-se, pois, que as regras que estabelecem essas dimensões influenciam o processo decisório na medida em que definem quem de fato pode tomar decisões.

Dessa forma, vejamos quais as contribuições de cada uma das correntes do neo-institucionalismo a partir da análise de seus pressupostos.

A perspectiva distributivista considera que o objetivo principal dos parlamentares é a reeleição. Assim, estes orientariam suas ações no sentido de atender às demandas de sua base eleitoral, buscando garantir, por exemplo, políticas que a beneficiem (benefícios concentrados), mas que tenham um custo para toda a população (custos difusos). No mesmo diapasão, o voto do eleitor seria formado através de um raciocínio "custo versus benefício", isto é, o parlamentar que conseguisse mais recursos para aquele eleitorado específico, obteria mais votos desse.

A perspectiva distributivista ainda destaca a importância do sistema de comissões, uma vez que essas possuiriam prerrogativas legislativas que permitiriam influenciar no processo de tomada de decisão. Nesse sentido, as comissões poderiam vetar propostas antes que essas chegassem ao plenário (gatekeeping powers) e propor e aprovar políticas não condizentes com a preferência do plenário, porque também teriam a "palavra final" no processo decisório, através das comissões de conferência. Vale destacar que os critérios para alocação dos parlamentares nas comissões seria a própria vontade desses parlamentares, isto é, os parlamentares teriam liberdade para escolher de quais comissões participariam (autosseleção).

Além disso, a perspectiva distributivista entende o sistema comissional como local em que os parlamentares negociam seus votos entre si com a finalidade de ga- 
rantir políticas distributivistas para o seu eleitorado específico, ou seja, as comissões induziriam a uma cooperação entre os parlamentares que operaria como uma espécie de "troca de favores" a partir do apoio a projetos de lei (logroll).

Por sua vez, a perspectiva informacional, que tem Keith Krehbiel (1991 apud LIMONGI, 1994) como seu principal autor, tem por base dois postulados: (1) todas as decisões do legislativo devem ser estruturadas de acordo com o princípio majoritário, isto é, todas as decisões são produto da vontade da maioria; (2) as decisões são tomadas num contexto de incerteza e assimetria informacional, condições que fariam com que os parlamentares buscassem mais informações, incentivando-os a se tornarem especialistas em certos temas.

Há uma oposição entre as versões distributivista e informacional. Primeiramente, Krehbiel destaca que é impossível às comissões passar por cima da vontade da maioria, uma vez que o regimento interno da câmara baixa norte-americana permite que os projetos sejam retirados das comissões mediante a assinatura da maioria dos membros da casa. Assim, as comissões não tem uma atuação tão autônoma como indica a perspectiva distributivista, nem os parlamentares conseguem aprovar seus projetos contando apenas com estratégias de logrolling.

O segundo ponto de oposição entre as duas versões está ligado à escolha dos parlamentares para as comissões. A versão informacional destaca que a lista de membros das comissões deve ser votada em plenário, e por isso, deve estar de acordo com o princípio majoritário. Para os distributivistas, essa votação seria um processo meramente formal, já que a autosseleção seria o critério de integração das comissões parlamentares.

Outra divergência entre essas duas versões diz respeito à função das comissões. Para o distributivismo, as comissões funcionam como um mercado de votos para a aprovação de políticas distributivistas. Já para a versão informacional, as comissões são estruturas responsáveis por ampliar o conhecimento sobre um determinado tema, a fim de reduzir a incerteza em relação aos resultados da política pública. Embora haja muitos pontos conflitantes, vale lembrar que ambas as versões consideram o sistema de comissões o eixo estruturador da atividade legislativa.

A versão partidária, por sua vez, afirma a importância dos partidos no processo de tomada decisão. 0 argumento é que os membros mais importantes dos partidos ocupam determinados cargos capazes de exercer grande influência no processo decisório. A versão partidária também afirma que as comissões devem ser entendidas como uma forma de governo partidário, porque os partidos são os responsáveis por elaborarem a lista de quais comissões os parlamentares participarão (vale lembrar que essa lista tem que ser votada em plenário), assim, caso algum parlamentar 
não esteja de acordo com as diretrizes partidárias, o partido pode puni-lo, não o alocando na comissão de sua preferência, por exemplo. Nesse sentido, Cox e McCubbins (2005) argumentam que os partidos políticos têm atuado como cartéis legislativos, buscando criar mecanismos de centralização decisória, ou seja, concentrar poderes em determinados cargos e dominar estes.

Os cartéis legislativos atuam no sentido de dominar as presidências das comissões e a presidência da câmara, cargos que permitem que esses controlem o processo decisório. Esse controle é exercido devido às diversas prerrogativas das quais gozam os cargos em questão, como gatekeepingpower (poder de agenda negativo, ou seja, poder de impedir que uma proposição seja apreciada) e poder de estabelecer a ordem do dia. Assim, Cox e McCubbins (2005) destacam que o cartel legislativo não está na sua atuação coesa ou, em outras palavras, na coincidência de interesses dos membros do partido. Em vez disso, está na (1) habilidade desse partido em definir a agenda, ou seja, estabelecer a ordem do dia e (2) habilidade de bloquear a entrada de questões controversas na agenda (party-splitting issues), através dos poderes de agenda negativos.

Por fim, os autores buscam explicar quais os critérios para a ocupação das posições de poder. Segundo eles, os critérios são (1) lealdade dos parlamentares ao partido e (2) senioridade, isto é, quanto maior o tempo de filiação ao partido, maior a possibilidade do parlamentar alcançar cargos importantes.

Como se pode perceber, em nenhum momento as abordagens acima tratadas incluem os assuntos de gênero em suas discussões. Não incluem o sexo do/a parlamentar entre as possíveis variáveis que explicam o acesso a postos críticos, também não procuram propor mecanismos que possam reverter a desigual representação política entre homens e mulheres nas comissões legislativas ${ }^{2}$. A suposta neutralidade das regras com relação a questões de gênero pode na verdade reforçar a desigualdade entre homens e mulheres no que refere à ocupação de posições de poder no Parlamento, indicando que, em vez de neutras, as regras são gender-blind, ou seja, indiferentes à desigualdade de gênero.

Heath, Schwindt-Bayer e Taylor-Robinson (2005) verificaram que há um viés de gênero no que diz respeito à alocação das parlamentares nas comissões legislativas em seis países latino-americanos, a saber: Argentina, Chile, Colômbia, Costa Rica, Honduras e Venezuela. Assim, o aumento do percentual de mulheres nesses legislativos é acompanhado de uma tendência de que as parlamentares sejam encaminhadas para as comissões relacionadas a questões de gênero ou "questões sociais (tradicionalmente consideradas como "femininas", como educação e assistência social)

2 http://www.idea.int/publications/parlamentos-sensibles-al-genero/upload/Gender-Mainstreaming-in-LA-Parliaments_inlay.pdf 
o que contribui para sua segregação, uma vez que elas acabam não participando de outras comissões mais centrais no que se refere ao processo decisório, como as relacionadas à constitucionalidade das proposições e finanças.

A questão que emerge, pois, diz respeito aos efeitos da regra do processo decisório no tocante à desigualdade de gênero, ou que regras podem ser mais ou menos inclusivas. O’Brien (2012) verifica que a mudança no sistema de recrutamento para presidências das comissões do Parlamento Britânico - antes orientadas pelas lideranças partidárias e atualmente, com a mudança, distribuídas através de eleições proporcionou o aumento do número de mulheres nessas posições, o que parece indicar que quanto mais descentralizado o processo de seleção, maiores as chances das mulheres ocupá-los.

Tal proposição precisa, no entanto, passar pelo crivo da análise empírica, uma vez que há variação nos países considerados na análise com relação aos mecanismos de seleção da presidência/mesa diretora da Câmara Baixa e comissões, havendo países em que todos os membros podem se candidatar a tais cargos (Argentina) e outros em que apenas podem se candidatar membros que pertencem à maioria (Costa Rica), dado que ilustra e reforça a necessidade de realização de verificação empírica dos efeitos dos diferentes desenhos institucionais.

Assim, é preciso pensar que contextos institucionais seriam mais favoráveis à inclusão de mulheres e ao seu acesso a postos críticos, como presidências de comissões legislativas e presidências de câmaras baixas. Essa questão nos leva à formulação de duas hipóteses.

A primeira delas não leva em consideração a classificação temática das comissões, tal como o fazem Heath et. al. (2005), uma vez que a definição da relevância das comissões deve considerar os interesses e estratégias dos atores, no caso, das e dos parlamentares e não apenas definições regimentais de prerrogativas de comissões. Nesse sentido, parlamentares envolvidos/as ou associados/as a determinados temas (issues) podem se sentir mais motivados a integrar comissões a eles associados que comissões tradicionalmente identificadas como centrais, como a de constituição e justiça. Enfatiza-se nessa hipótese a noção de representação descritiva e o percentual de mulheres eleitas é considerado elemento-chave para se analisar a representação de mulheres.

H1: quanto maior o percentual de mulheres em legislaturas, maior o percentual de mulheres em presidências de comissões.

A segunda hipótese se aproxima do argumento de Binder (1997) e de O’Brien (2012), que indicam que direitos de minorias políticas e partidárias em geral se traduzem como direitos garantidos a parlamentares individuais e que regras menos 
centralizadas em lideranças partidárias garantem maior possibilidade de inclusão de minorias, como as mulheres.

H2: Quanto menos centralizado o processo decisório, maior a chance de que mulheres ocupem presidência de comissões.

\section{Materiais e métodos}

As fontes utilizadas para desenvolvermos a pesquisa consistiram nos regimentos internos das câmaras baixas dos países analisados (dados primários), nos dados disponíveis no sítio do Interparlamentary Union (IPU) 3 e nos dados disponíveis no Observatorio del Poder Legislativo en América Latina (LEGISLATINA) ${ }^{4}$ (dados secundários). 0 ano de 2010 foi tomado referência para coleta de dados.

Em relação aos métodos, realizamos pesquisa documental e estudos comparativos dos regimentos internos das câmaras baixas dos oito países pesquisados. Por fim, fizemos análises descritivas dos aspectos institucionais de cada câmara procurando estabelecer uma escala de centralização/descentralização do processo de tomada de decisão. Essa escala foi posteriormente utilizada para se realizar algumas análises estatísticas de forma a testar as hipóteses apresentadas anteriormente.

Foram calculados os coeficientes de correlação de Pearson entre as seguintes variáveis: grau de centralização, \% mulheres no legislativo, \% mulheres em presidências de comissões, com a finalidade de identificar a relação entre cada par de variáveis. 0 nível de significância adotado foi de 5\%. Para tanto, o software utilizado foi o SSPP (versão 21.0, 2012).

\section{Discussão, resultados e conclusões}

A primeira dimensão que analisaremos é como se dá o estabelecimento da ordem do dia, ou seja, quem define as matérias que serão deliberadas no plenário.

Como instrumentos de análise, utilizaremos as categorias elaboradas por Aleman e Tsebelis (2002) para entender o processo de tomada de decisão nos países da América Latina. De acordo com esses autores, o estabelecimento da ordem do dia pode se dar de quatro formas possíveis. A primeira é uma espécie de consenso entre os partidos políticos, o que permitiria que todos partidos políticos pudessem incluir projetos na ordem do dia.

Dentre os países analisados, nenhum se encaixa perfeitamente nessa primeira forma de definição da ordem do dia. Um bom exemplo é o caso da Costa Rica, 
em que o processo de definição da ordem do dia acontece através do consenso entre os partidos políticos, mas também através de um mecanismo que leva em conta o "peso" do partido político na Câmara, ou seja, quanto maior o número de parlamentares deste partido, maior o número de proposições que ele poderá incluir na ordem do dia. Assim, na Costa Rica, todos os partidos políticos tem o direito de incluir pelo menos uma proposição na ordem do dia, devido ao caráter consensual que há no seu processo de estabelecimento da ordem do dia, apesar do maior peso dado às preferências do partido majoritário. Além dessa forma consensual, em alguns países a ordem do dia é definida exclusivamente pelo presidente da Câmara. Esse é o caso do Uruguai, Equador e do Brasil.

Já a terceira forma de estabelecimento da ordem do dia consiste em uma decisão conjunta dos líderes partidários e das autoridades da Câmara, o que indica certa descentralização das decisões. Dentre os países de nossa amostra, somente a Argentina adota esse mecanismo. Por fim, restam três países em que as autoridades da mesa diretora são as responsáveis pelo estabelecimento da ordem do dia: Paraguai e México e Bolívia. Neste último país, é interessante ressaltar que o primeiro secretário da mesa diretora - que é, necessariamente, membro da maioria - é o responsável por propor a ordem do dia ao presidente. Diante disso, defendemos que é pertinente considerar o cargo de primeiro secretário como um posto crítico.

Assim, com base na forma de estabelecimento da ordem do dia, podemos criar uma tabela comparando a centralização decisória nos países analisados:

Tabela 1: Definição da ordem do dia (V1).

\begin{tabular}{|c|c|c|}
\hline Quem estabelece a ordem do dia? & Países & Peso \\
\hline Presidente da câmara & Uruguai, Brasil, Equador. & 2.0 \\
\hline Autoridades da mesa diretora & Paraguai, México e Bolívia. & 1.5 \\
\hline $\begin{array}{c}\text { Líderes partidários e autoridades } \\
\text { da mesa diretora }\end{array}$ & Argentina & 0.75 \\
\hline Forma consensual & Costa Rica* & 25 \\
\hline
\end{tabular}

Fonte: elaboração própria a partir dos dados dos regimentos internos das câmaras baixas dos países em questão.* Na Costa Rica, todos os líderes partidários teriam o direito de ter pelo menos uma de suas proposições incluídas na ordem do dia.

Atribuímos valores maiores às categorias que indicam maior centralização do processo decisório. Assim, aos países em que o presidente da câmara é o responsável por definir a ordem do dia, atribuímos três pontos; já para os casos em que a definição da ordem do dia acontece de forma um pouco menos centralizada - decisão das autoridades da mesa diretora - atribuímos valores menores, como indica a Tabela1.

Em relação à Argentina, país no qual a elaboração da ordem do dia se dá de forma relativamente descentralizada, atribuímos peso um pouco menor. Por fim, 
atribuímos o peso mais baixo à Costa Rica, pois, como vimos, é o país no qual o estabelecimento da ordem do dia se dá de forma mais descentralizada.

É importante destacar que estamos atribuindo pontos a cada característica institucional com a finalidade de podermos, ao final do trabalho, analisar conjuntamente as quatro variáveis e classificar os países da amostra em relação ao grau de centralização do processo de tomada de decisão em suas respectivas câmara baixa.

A segunda dimensão que analisaremos é qual o grau de dificuldade para se modificar a ordem do dia. Nesse sentido, é correto afirmar que quanto mais difícil é o processo de modificação da ordem do dia, mais descentralizado é o processo de tomada de decisão, haja vista a necessidade de anuência de um número maior de atores políticos.

Utilizaremos duas categorias criadas por Aleman e Tsebellis para classificar as possíveis formas de mudança da ordem do dia, a saber: (1) é necessário o apoio de maioria absoluta do plenário para modificar a ordem do dia; (2) é necessário apoio de maioria qualificada do plenário para modificar a ordem do dia.

Destarte, no primeiro caso, em que há exigência de maioria absoluta, haveria maior centralização, uma vez que a prerrogativa de modificar a ordem do dia recairia em um menor número de atores políticos. De outro modo, a exigência de maioria qualificada, por exigir consenso mais amplo no que toca à alteração da ordem do dia, denotaria caráter mais descentralizado, atribuindo maior importância ao voto de cada ator político individualmente considerado.

A tabela a seguir classifica os países de acordo com as possíveis formas de alterar a ordem do dia:

Tabela 2: Maiorias necessárias para alteração da ordem do dia (V2).

\begin{tabular}{|c|c|c|}
\hline Maioria necessária & Países & Peso \\
\hline Absoluta & $\begin{array}{c}\text { Brasil, México, Equador e Uru- } \\
\text { guai. }\end{array}$ & 1.5 \\
\hline $\begin{array}{c}\text { Maioria qualificada (dois terços } \\
\text { dos votos) }\end{array}$ & $\begin{array}{c}\text { Bolívia, Paraguai, Costa Rica e Ar- } \\
\text { gentina. }\end{array}$ & \multicolumn{2}{|c|}{} \\
\hline Fonte: elaboração própria a partir dos dados dos regimentos internos das câmaras baixas dos países em questão.
\end{tabular}

Dentre os países de nossa amostra, Argentina, Brasil, Uruguai, México e Equador estão abarcados pela primeira forma de se modificar a ordem do dia. É importante chamar atenção para o caso da Argentina, que, a depender do estado de desenvolvimento do assunto em questão, poderá se encaixar tanto na primeira como no segundo parâmetro de classificação . Diante dessa dúvida, nos orientamos pelo trabalho de Aleman e Tsebelis (2002), que classificaram a Argentina na segunda dimensão, considerando que nesse país é necessário maioria de dois terços dos votos 
para se modificar a ordem do dia.

No caso do Brasil, também é necessário maioria absoluta para a alteração da ordem do dia. Vale lembrar que o requerimento para mudar a ordem do dia deve contar com maioria absoluta dos deputados ou líderes partidários que representem esse número. Essa prerrogativa dos líderes partidários - poder falar em nome de toda a bancada - coloca-os em posição de influenciar decisivamente o processo decisório.

O Uruguai permite que haja alteração na ordem do dia através da aprovação de uma maioria absoluta. Além disso, através do pedido de urgência, que deve ser feito pelo primeiro orador, pode-se interromper a apreciação de um assunto e fazer com que outro assunto se torne o primeiro da ordem do dia.

Já no caso do México, somente a Mesa diretora - composta pelo presidente da câmara e os secretários das comissões permanentes - tem o poder de propor alguma modificação na ordem do dia, que serão submetidas ao presidente, e este submeterá à votação do plenário.

O último país que exige maioria absoluta para modificar a ordem do dia é o Equador. 0 processo se dá da seguinte forma: antes do horário estabelecido para a instalação da sessão, cerca de pelo menos 5\% dos deputados devem apresentar à secretaria-geral da assembleia nacional uma petição escrita para a inclusão de uma proposta. Essa proposta necessitará do apoio de mais da metade do congresso para que ela seja integrada à ordem do dia. É importante destacar que cada legislador só pode apoiar uma proposta de modificação por sessão.

Finalizada a análise dos países do primeiro grupo, analisaremos os países que possuem um caráter mais descentralizador no que se refere ao processo decisório, são eles: Bolívia, Paraguai e Costa Rica. Em todos esses casos é necessária maioria qualificada de dois terços para se alterar a ordem do dia. Todavia, é importante destacar que somente o regimento interno da câmara da Costa Rica prevê restrições no que diz respeito à proposição de mudança na ordem do dia. Nesse país, é necessário que a referida proposição seja feita por (1) dois ou mais chefes de frações parlamentarias que juntos representem pelo menos dois terços dos deputados; (2) pelo menos a metade dos chefes de frações parlamentárias; (3) dez deputados que pertençam pelo menos à duas frações parlamentarias.

A importância de se destacar esses requisitos necessários para a proposição de monção que vise à mudança da ordem do dia está relacionada à ideia de posto crítico. Nesse diapasão, pode-se perceber que os líderes partidários gozam de certo privilégio na Costa Rica - assim como no caso do Brasil - que é falar em nome de todos os deputados pertencentes a seu partido (ou fração parlamentaria).

A terceira dimensão a ser analisada está relacionada à possibilidade de que 
certos projetos sejam votados em plenário sem ter de passar pelas comissões. É importante chamar atenção para o fato de que analisaremos apenas quais os mecanismos internos das Câmaras Baixas permitem que um projeto não tenha de passar pela comissão. Assim, não incluiremos em nossa análise quaisquer mecanismos - que por mais que possibilitem que um projeto seja apreciado no plenário sem passar pelas comissões - que sejam prerrogativas de outra instituição que não a Câmara Baixa analisada. Dito isso, poderemos iniciar a análise da terceira dimensão. Para isso, criamos uma tabela que busca enquadrar os países em duas categorias:

Tabela 3: Possibilidade de votação de projetos sem discussão prévia nas comissões (V3).

\begin{tabular}{|c|c|c|}
\hline $\begin{array}{c}\text { Há possibilidade de que o projeto } \\
\text { seja votado no plenário sem antes } \\
\text { passar pelas comissões? }\end{array}$ & Países & Peso \\
\hline Sim & $\begin{array}{l}\text { Argentina, Paraguai, Costa Rica, } \\
\text { México. }\end{array}$ & 3 \\
\hline Não & Bolívia, Brasil, Equador, Uruguai. & 1,5 \\
\hline
\end{tabular}

O primeiro país a ser analisado é a Argentina. Nesse país, é necessário o apoio de dois terços da câmara para que um projeto não passe pela fase de comissão e seja encaminhado diretamente para a apreciação do plenário. Contudo, deve-se destacar que projetos relacionados a gastos só podem tramitar no plenário depois do despacho da comissão.

O segundo país que analisaremos é o Paraguai. Diferentemente da Argentina, no caso do Paraguai é necessário apenas maioria simples para retirar um projeto da fase de comissão, o que confere um menor o grau de autonomia às comissões paraguaias. Por fim, na Costa Rica e no México também há a possibilidade de que projetos sejam apreciados sem passar pela fase de comissões. Devo ressaltar que no caso do México este processo se dá somente por meio do pedido de urgência.

O próximo país a ser analisado é a Bolívia. Nesse caso, os projetos só podem ser apreciados pelo plenário sem passar pela fase de comissões em duas situações: (1) quando esgota o prazo de apreciação do projeto na comissão; (2) quando o projeto se refere a desastres naturais ou distúrbios internos. Como podemos perceber, não há a possibilidade de que, por meio de votação interna do plenário, um projeto seja retirado da comissão. Isso confere às comissões bolivianas - possuem poder de agenda negativo - maior grau de autonomia quando comparadas às comissões dos países do primeiro grupo.

É importante destacar que, por mais que exista a possibilidade de projetos 
serem apreciados pelo plenário sem passar pela fase de comissões, a Bolívia é incluída no segundo grupo pois os mecanismos que permitem a retirada de projetos das comissões não constituem prerrogativas de nenhum posto crítico.

Já nos casos do Brasil, Equador e Uruguai, para que um projeto seja apreciado pelo plenário, ele tem necessariamente que passar pela fase de comissão.

A quarta e última dimensão que analisaremos está relacionada aos mecanismos regimentais que possibilitam o encerramento do debate e, consequentemente, a votação do projeto. A tabela a seguir mostra qual desses critérios os países de nossa amostra utilizam:

Tabela 4: Restrição do debate antes de votação final de um projeto de lei no plenário (V4).

\begin{tabular}{|c|c|c|}
\hline $\begin{array}{l}\text { Mecanismo que possibilita o en- } \\
\text { cerramento do debate. }\end{array}$ & Países & Peso \\
\hline $\begin{array}{c}\text { Decisão das autoridades da mesa } \\
\text { diretora }\end{array}$ & Argentina, Equador, México. & 3 \\
\hline Maioria Absoluta (ou simples) & Brasil, Paraguai e Costa Rica & 2 \\
\hline Maioria qualificada & Bolívia e Uruguai & 1 \\
\hline
\end{tabular}

Analisaremos primeiro os países em que a decisão sobre o encerramento do debate ocorre de forma mais centralizada, a saber: Argentina, Equador e México. No primeiro caso, o presidente da câmara pode encerrar o debate quando julgar que o assunto já foi discutido o bastante. Vale lembrar que é necessário o consentimento dos membros da comissão responsável pela matéria em questão. Já no caso do Equador e do México, não é necessário o consentimento dos membros da comissão. Desta forma, o presidente da câmara pode finalizar o debate quando julgar que a matéria já foi discutida o suficiente.

Em relação ao segundo grupo de países (Brasil, Paraguai e Costa Rica), eles utilizam um critério de encerramento do debate menos centralizado, isto é, é necessário apoio de maior número de parlamentares para que o debate se encerre. Por fim, a Bolívia e o Uruguai utilizam o critério mais descentralizado para o encerramento do debate: maioria qualificada de dois terços.

A tabela a seguir consiste na soma dos pesos que cada país obteve nas quatro tabelas anteriores. Dessa forma, o total indica o grau de centralização do país. Assim, quanto maior o valor total, mais centralizado é o processo decisório na câmara baixa do respectivo país. 
Tabela 5: Índice de centralização do processo decisório nas câmaras baixas (V5).

\begin{tabular}{|c|c|c|c|c|c|}
\hline País & V1 & V2 & V3 & V4 & Total \\
\hline México & 2,25 & 3,0 & 3,0 & 3,0 & 11,25 \\
\hline Equador & 3,0 & 3,0 & 1,5 & 3,0 & 10,5 \\
\hline Brasil & 3,0 & 3,0 & 1,5 & 2,0 & 9,5 \\
\hline Argentina & 1,5 & 1,5 & 3,0 & 3,0 & 9,0 \\
\hline Paraguai & 2,25 & 1,5 & 3,0 & 2,0 & 8,75 \\
\hline Uruguai & 3,0 & 3,0 & 1,5 & 1,0 & 8,5 \\
\hline Costa Rica & 0,75 & 1,5 & 3,0 & 2,0 & 7,25 \\
\hline Bolívia & 2,5 & 1,5 & 1,5 & 1,0 & 6,25 \\
\hline
\end{tabular}

Fonte: Regimentos Internos das Câmaras Baixas dos países e Aleman e Tsebelis (2002).

Como se pode perceber, há uma diferença significativa entre os países de nossa amostra no que diz respeito ao grau de centralização do processo decisório de suas respectivas câmaras baixas. Dito isso, verificaremos agora se o grau de centralização está correlacionado estatisticamente com o percentual de parlamentares do sexo feminino e com percentual de mulheres que ocupam a presidência de comissões.

Tabela 6: Grau de centralização do processo decisório, percentual de mulheres na legislatura e percentual de mulheres na presidência de comissões permanentes.

\begin{tabular}{|c|c|c|c|}
\hline País & Grau de centralização & $\begin{array}{c}\text { \% de mulheres na legis- } \\
\text { latura }\end{array}$ & $\begin{array}{c}\text { \% de mulheres em presi- } \\
\text { dência de comissão }\end{array}$ \\
\hline México & 11,25 & 26,2 & 18,2 \\
\hline Equador & 10,5 & 32,3 & 5,26 \\
\hline Brasil & 9,5 & 8,6 & 40 \\
\hline Argentina & 9 & 42,00 & 12,5 \\
\hline Paraguai & 8,75 & 12,5 & 35,7 \\
\hline Uruguai & 8,5 & 15,2 & 16,7 \\
\hline Costa Rica & 7,25 & 38,6 & 25,4 \\
\hline Bolívia & 6,25 & & \\
\hline
\end{tabular}

Fonte: Regimentos Internos das Câmaras Baixas dos países e Aleman e Tsebelis (2002).

Para a adequada compreensão da tabela faz-se necessário destacar que o p -valor encontrado na correlação entre grau de centralização e \% de mulheres na legislatura não foi significativo, visto que 0,8478 é maior, em módulo, do que 0,05, por isso, a correlação entre essas variáveis não foi significativa. Do mesmo modo, o p -valor encontrado na correlação entre grau de centralização e \% de mulheres na presidência de comissão também não foi significativo, visto que 0,7144 é maior do 
que 0,05 , não havendo, outrossim, significativa correlação entre as variáveis citadas. Contudo, o p -valor encontrado na correlação entre \% de mulheres na legis-

Tabela 7: Correlação entre grau de centralização do processo decisório, percentual de mulheres na legislatura e percentual de mulheres na presidência de comissões permanentes.

\begin{tabular}{|c|c|c|c|}
\hline & $\begin{array}{c}\text { Grau de centralização do } \\
\text { processo decisório }\end{array}$ & $\begin{array}{c}\text { \% mulheres na legisla- } \\
\text { tura }\end{array}$ & $\begin{array}{c}\text { \% mulheres na presidên- } \\
\text { cia de comissões }\end{array}$ \\
\hline $\begin{array}{c}\text { Grau de centralização do } \\
\text { processo decisório }\end{array}$ & 1 & $-0,0815$ & $-0,1928$ \\
\hline $\begin{array}{c}\% \text { mulheres na legisla- } \\
\text { tura }\end{array}$ & $-0,0815$ & 1 & 0,9766 \\
\hline $\begin{array}{c}\% \text { mulheres na presidên- } \\
\text { cia de comissão }\end{array}$ & $-0,0815$ & 0,9766 & 1 \\
\hline
\end{tabular}

latura e \% de mulheres na presidência de comissão foi significativo, visto que 0,0008 é menor do que 0,05 , podendo-se, portanto, afirmar que a correlação entre as variáveis citadas foi significativa.

Desta feita, a análise dos dados acima indica que nossa primeira hipótese não pode ser rejeitada, ou seja, podemos afirmar que quanto maior o número de mulheres na legislatura, maior o número de mulheres que ocupam presidências de comissões. Entretanto, outras análises mais refinadas, considerando uma classificação das comissões segundo sua importância relativa no que tange ao processo decisório seria importante para avaliar se, de fato, as mulheres ocupam postos críticos no poder Legislativo ou se apenas são designadas para presidências de comissões menos relevantes.

Já a segunda hipótese - quanto mais centralizado o processo decisório, menor a chance de que mulheres ocupem postos críticos - deve ser rejeitada, uma vez que a análise de correlação não apresentou significância estatística, apesar do sinal negativo indicar que a correlação, se fosse significativa, se apresentaria no sentido esperado: quanto maior a centralização, menor o percentual de mulheres nas presidências de comissões permanentes.

Esses resultados parecem indicar que a questão da inclusão das mulheres está relacionada não ao recrutamento ou seleção de mulheres para postos críticos, dimensão avaliada a partir das regras que configuram processos decisórios mais ou menos centralizados (H2), e que se refere à dimensão da demanda (Norris e Lovenduski, 1995). Pelo contrário, a inclusão de mulheres em postos críticos parece estar relacionada à dimensão da oferta (Norris e Lovenduski, 1995), uma vez que o maior 
percentual de mulheres na legislatura está forte e positivamente correlacionado ao maior percentual de mulheres em presidências de comissões legislativas (H1). Assim, o passo seguinte às análises aqui desenvolvidas é avaliar as características individuais dos legisladores e legisladoras, de forma a verificar se essas são relevantes para se explicar a ocupação de postos críticos nas câmaras baixas analisadas, considerando também a categorização temática das comissões, como fazem Heath et. al (2005).

Por fim, é importante mencionar os limites da análise desenvolvida, relacionados ao pequeno número de casos analisados e a seu caráter exploratório. Nesse sentido, devemos mencionar que os resultados da análise de correlação apontam apenas se e como as variáveis analisadas se associam, sem permitir a realização de inferências causais. Entretanto, acreditamos que tais limites devem ser tomados como incentivos a que novas pesquisas sejam realizadas, com o fim de saná-los e ampliar o escopo da análise desenvolvida.

\section{Referências bibliográficas}

ALEMÁN, E; TSEBELIS, G. Agenda Control in Latin American Presidential Democracies. American Political Science Association Annual Meeting, 2002, Boston, p.1-68.

ARAÚJO, Clara. As cotas por sexo na competição legislativa: o caso brasileiro em comparação com experiências internacionais. Dados, n.1, v. 44, p. 155-195, 2001.

BINDER, Sarah A. Minority Rights, Majority Rule: Partisanship and the Development of Congress. Cambridge, UK; New York, NY: Cambridge University.

COX, Gary. The organization of democratic legislatures. In: WEINGAST, B. and WHITTMAN, D (ed.). The Oxford Handbook of Political Economy. Oxford: Oxford University Press, 2005.

HEATH, R. M.; SCHWINDT-BAYER, L. A.; TAYLOR-ROBINSON, M. M. Women on the sidelines: women's representation on committees in Latin American legislatures. American Journal of Political Science, v. 49, n.2, p. 420-436, 2005.

IDEA. Electoral System Design: An Overview of the New International IDEA Handbook, Stockholm, 2005.

LIMONGI, Fernando. O Novo Institucionalismo e os estudos legislativos: a literatura norte-americana recente. BIB, n. 37, 1994.

LIMONGI, Fernando. O Poder Executivo na Constituição de 1988. In: OLIVEN, Ruben George; RIDENTI, Marcelo; BRANDÃO, Gildo Marçal. A Constituição de 1988 na vida brasileira. São Paulo: Hucitec, 2008, p. 23 - 56. 
LIMONGI, F.; FIGUEIREDO, A. C. (1998), As Bases Institucionais do Presidencialismo de Coalizão. Lua Nova. Revista de Cultura e Política, São Paulo, v. 44, p. 81-106.

NORRIS, P.; LOVENDUSKI, J. Political Recruitment: Gender, Race and Class in the British Parliament. Cambridge: Cambridge University Press, 1995.

O'BRIEN, D. Z. Gender and select committee elections in the British House of Commons. Politiccs and Gender, n.8, p. 178-204. 2012.

PITKIN, Hannah Fenichel. The concept of representation. Berkeley: University of California Press, 1967.

POLSBY, N. The institutuinalization of U.S. House of Representatives. The American Political Science Review, v. 62, n.1, 1968.

REYNOSO, Diego. La diversidad institucional del bicameralismo en América Latina. Perf. latinoam, México, v. 18, n. 35, jun. 2010. Disponível em <http://www.scielo.org. $\mathrm{mx} /$ scielo.php?script=sci_arttext\&pid=S0188-76532010000100005\&lng $=$ es\&nrm= iso>. Acesso em 23 maio 2014.

REZENDE, Daniela Leandro. Gênero e representação política das mulheres na América Latina. Projeto de tese apresentado ao Departamento de Ciência Política, Universidade Federal de Minas Gerais. Belo Horizonte, 2013.

Qual o lugar reservado às mulheres? Uma análise generificada de comissões legislativas na Argentina, no Brasil e no Uruguai. 2015. Tese (Doutorado em Ciência Política). Faculdade de Filosofia e Ciências Humanas, Universidade Federal de Minas Gerais, Belo Horizonte. 2015.

ROCHA, Marta Mendes da; BARBOSA, Cássio Felipe. Regras, incentivos e comportamento: as comissões parlamentares nos países do Cone Sul. Rev. Sociol. Polit., Curitiba, v.16, supl. ago. 2008. Disponível em <http://www.scielo.br/scielo.php?script=sci_ arttext\&pid=S0104-44782008000300007\&lng=pt\&nrm=iso $>$. Acesso em 23 maio 2014.

TSEBELIS, George. Veto players: How political institutions work. New Jersey: Princeton University Press, 2002.

Recebido em Agosto/ 2014.

Aprovado Março/2016. 